Editorial

\title{
Biological markers of oxidative stress in exhaled air
}

\author{
Chrsitian Sarbach ${ }^{1}$ and Eric Postaire ${ }^{2 \star}$ \\ ${ }^{1}$ Ar2i. Le Plessis-Robinson, France \\ ${ }^{2}$ Academy Science, Paris, France
}

\section{Nearly all energy production in living organisms is by oxidation reactions (fires are large oxidative embers)}

Oxidation reactions produce, through complex intermediate steps, small energy packages that are more easily stored than a sudden combustion oxidation. The slow and controlled production of energy in a nuclear power plant allows its use, a massive explosion produces the result that we know ... It's the same thing in our bodies. These reactions are never $100 \%$ efficient, not all the energy produced is used as bio fuel. Indeed, during the intermediate stages, they induce a deterioration of cells and tissues by consuming about $10 \%$ of this energy. They cause significant "wear and tear" when there is no longer any compensation for these parasitic oxidations. The latter can be excessively used in pathological situations inducing inflammatory reactions, or simply during metabolic overproduction, or even simple intense and prolonged efforts.

It all starts with the activation of $\mathrm{O}_{2}$ by the energy produced in the body to give rise to "Reactive Oxygen Species"

The energy activates oxygen to promote the production of "Reactive Oxygen Species" (ROS) (improperly called free radicals) such as singlet oxygen $\left(\mathrm{O}_{2}{ }^{1}\right)$, superoxide anion $\left(\mathrm{O}_{2}{ }^{-}\right)$, hydroxy radical $(\mathrm{OH})$, etc. These ROS then act on biological molecules (lipids, proteins, DNA, etc.) to oxidize them and thus cause (i) ageing of the cell and (ii) chronic pathologies.

Precisely quantifying the importance of these parasitic reactions and thus the intensity of the "wear and tear" of the organism is an objective that has been sought but never achieved

The stakes are high because, while our genetic heritage allows us to set up enzymatic systems to repair the chemical damage caused, the phenomena of "wear and tear" are prevented by exogenous elements. It is therefore essential to quantify both normal oxidation (a regulated energy production) and pathological oxidation (fire); a distinction must be made between the two in order to provide the appropriate compensation necessary to maintain homeostasis. Everything happens like in an internal

\section{More Information}

*Address for Correspondence: Eric Postaire, Academy Science, Paris, France, Tel: +33 63713 75 28; Email: eric.postaire@academie-sciences.fr

Submitted: 17 January 2020

Approved: 30 January 2020

Published: 31 January 2020

How to cite this article: Sarbach C, Postaire E. Biological markers of oxidative stress in exhaled air. Arch Pharm Pharma Sci. 2020; 4: 010-012.

DOI: dx.doi.org/10.29328/journal.apps.1001021

Copyright: @ 2020 Sarbach C, et al. This is an open access article distributed under the Creative Commons Attribution License, which permits unrestricted use, distribution, and reproduction in any medium, provided the original work is properly cited.

Check for updates

OPEN ACCESS

combustion engine or a steam locomotive: we must avoid the engine getting out of control, in order to preserve it and make it last longer [1].

We can recall here the close relationship between biooxidation and the mechanisms of ageing, described by many scientists. Many methods have been proposed which have in common that they provoke a strongly oxidizing reaction with chemical reagents and evaluate the rate of neutralization of these reactions. Most of the time, it is indeed a question of measuring the quantity of substrate that can be consumed or the capacity to limit the combustion of these substrates.

After the fire we can measure the combustion residues the "ashes"

After a forest fire, the vegetation gives way to mounds of ashes and small fragments. The quantity of ashes and small fragments is an indication of the intensity of the disaster. The same is true for the burning of biological cells and tissues. The biological molecules that have been combined give way to small molecules, the quantity of which also shows the extent of the devastating effect. Thus constituents of the cell membrane such as unsaturated fatty acids are destroyed into small, often volatile molecules (mostly alkanes, such as ethane or pentane) such as ash and twigs. The volatile compounds formed are then eliminated through the lungs.

The amount of fire extinguishers used to contain a fire also reflects its importance

The best-known fire extinguishers are water and $\mathrm{CO}_{2}$ (oxygen deprivation too). But there are other less famous 
extinguishers that act through different mechanisms: by reducing the energy at the heart of the flame (thus the heat, thus the intensity of the flames) for example. This is the case of freons or CFCs (chlorofluorocarbons) and halons, better known as propellant gas in aerosols, refrigerant fluid causing cooling of refrigerator pipes - and agents responsible for "holes" in the ozone layer...). By the way, how do freons destroy the ozone layer? By reducing ozone $\mathrm{O}_{3}$ into oxygen $\mathrm{O}_{2}$, i.e. by behaving like powerful antioxidants! They are also used in fire fighting thanks to their anti-oxidant properties.

Well, it turns out that our bodies are capable of producing them during cellular radical reactions. These "endogenous freons", real physiological extinguishers, are only produced when the cell needs them thanks to a subtle energetic control of their biosynthesis [2]. They act in the same way as fire extinguishers by reducing the energy of the "reactor" (the mitochondria of the cell in humans), which limits the production of ROS...

These compounds are also eliminated through the lungs. They are not found in healthy, resting individuals. Their concentration and the length of time they are present in the exhaled air are evidence of the intensity of the bio-fire they helped extinguish. Hence to imagine inhaling freons (very low toxicity at low concentrations) to help the organism in certain pathological cases? So we still have to recover these compounds (ashes and fire extinguisher) in the exhaled air.

\section{Explanation of the phenomena}

Production of halogenated alkanes by halogenation of a double bond

$$
\text { R- } \mathrm{CH}=\mathrm{CH}-\mathrm{R}+\mathrm{X}_{2} \longrightarrow \mathrm{R}-\mathrm{CH}-\mathrm{C}-\stackrel{\mathrm{CH}}{\mathrm{C}}-\mathrm{R}
$$

Production of halogenated alkanes by reaction of alkanes on halogens

Methane, ethane and other alkanes react with the first three members of the halogen family: fluorine, chlorine and bromine. They do not react significantly with iodine. The reaction of an alkane with a halogen is a substitution reaction called halogenation.

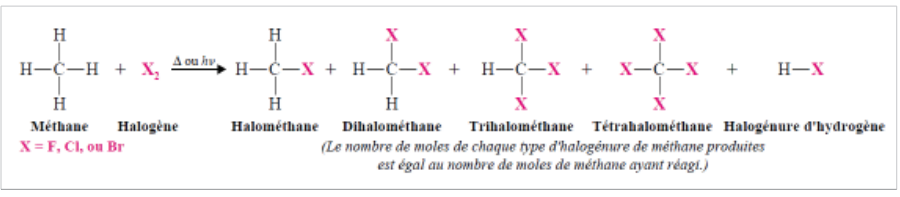

\section{Production of halogenated alkanes by radical halogenation of alkanes}

The halogenation reactions of alkanes proceed by a radical mechanism.
- The reaction is initiated by an energy supply (traditionally heat or light).

- The activation of the reaction by photons is very effective.

- Upper alkanes react with halogens according to a chain reaction mechanism: initiation, propagation and terminaison.

$$
\begin{aligned}
& \text { MÉCANISME DE LA RÉACTION } \\
& \text { Halogenation radicalaire de l'ethane } \\
& \text { Amorçage } \\
& \text { Étape } 1 \\
& \text { Propagation } \\
& \text { Étape } 2 \\
& \text { Étape } 3 \\
& \mathrm{CH}_{3} \mathrm{CH}_{2} ; \mathrm{H}+\mathrm{Cl} \longrightarrow \mathrm{CH}_{3} \mathrm{CH}_{2} \cdot+\mathrm{H}: \mathrm{Cl}
\end{aligned}
$$

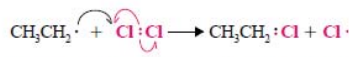

$$
\begin{aligned}
& \text { La propagation se poursuit par la répétition des étapes } 2 \text { et } 3 \text {. } \\
& \text { Terminaison } \\
& \mathrm{CH}_{3} \mathrm{CH}_{2} \cdot \mathrm{N}_{+} \cdot \mathrm{Cl} \longrightarrow \mathrm{CH}_{3} \mathrm{CH}_{2}: \mathrm{Cl} \\
& \mathrm{CH}_{3} \mathrm{CH}_{2} \cdot 2 \curvearrowleft+\mathrm{CH}_{2} \mathrm{CH}_{3} \longrightarrow \mathrm{CH}_{3} \mathrm{CH}_{2}: \mathrm{CH}_{2} \mathrm{CH}_{3} \\
& \mathrm{Cl}^{\mathrm{N}+} \cdot \mathrm{Cl} \longrightarrow \mathrm{Cl}: \mathrm{Cl}
\end{aligned}
$$

Production of halogenated alkanes - Thermodynamic principles

- The lower reactivity of chlorine compared to fluorine is partly explained by the fact that the activation energy of the first propagation step is higher than that of fluoridation (16 kJ.mol-1 for $\mathrm{Cl}_{2}$ and $5 \mathrm{~kJ} \cdot \mathrm{mol}^{-1}$ for $\mathrm{F}_{2}$ ).

- The higher energy required to break the chlorinechlorine bond during priming also influences reactivity.

- But it is probably the overall heat of the fluoridation reaction, which is much higher, that better explains the higher reactivity of fluorine.

- The values of the reaction energies are compatible with particular physiopathological conditions.

\section{Halogenated alkanes mechanism}

Few halogenated alkanes as halothane, isoflurane and sevoflurane have been investigated to evaluate their effects on electron transport chain activity. These compounds have shown to reversibly increased NADH fluorescence in intact ventricular myocytes of ginea-pig, suggesting that NADH oxidation was impaired. Globally these halogenated alkanes inhibit complex I (NADH: ubiquinone oxidoreductase) of the electron transport chain of mitochondria. This inhibition of respiration leads to mitochondrial membrane hyperpolarization dependent on the utilization of glycolytic ATP by the $\mathrm{F}_{1} \mathrm{~F}_{0}$-ATPase and other transporters acting in reverse mode. Recently, several groups have reported that, after treatment of a variety of cells with pro-apoptotic stimuli, there is an early phase of mitochondrial hyperpolarization. This has been shown to precede the generation of free radicals. 
The results obtained in our experiments suggest that endogenous fluoroalkanes can inhibit the complex I. of the electron transfer chain (Table 1). These alkanes produced during stress would precede the generation of free radicals and would work as endogenous antiradical substances. This hypothesis is sustained by the chemical inhibition of diffusion flames through addition of halogenated inhibitors as trifluoromethane and the possible reaction of halogenofluorocarbons with superoxide ion.

\begin{tabular}{|c|c|c|c|c|c|c|c|c|c|c|}
\hline & Normal & Control & $\mathrm{CCl}_{3} \mathrm{~F}$ & $\mathrm{CCl}_{2} \mathrm{~F}_{2}$ & $\mathrm{C}_{2} \mathrm{Cl}_{3} \mathrm{~F}_{3}$ & $\mathrm{C}_{2} \mathrm{Cl}_{2} \mathrm{~F}_{4}$ & $\mathrm{C}_{2} \mathrm{Cl}_{2} \mathrm{~F}_{3}$ & $\mathrm{C}_{2} \mathrm{Cl}_{3} \mathrm{~F}_{2}$ & $\mathrm{C}_{2} \mathrm{Cl}_{2} \mathrm{BrF}_{3}$ & $\mathrm{C}_{2} \mathrm{CIF}_{4}$ \\
\hline Normal & 108 & 108 & 115 & 100 & 135 & 110 & 112 & 121 & 125 & 105 \\
\hline $\begin{array}{c}\text { Serum } \\
\text { withdrawal }\end{array}$ & & 49 & 40 & 42 & 94 & 65 & 70 & 85 & 88 & 50 \\
\hline SD1 & & 7 & 5 & 4 & 8 & 12 & 9 & 5 & 6 & 355 \\
\hline SD2 & & 2 & 3 & 2 & 5 & 3 & 5 & 5 & 8 & 2 \\
\hline
\end{tabular}

Effect of the halogenated alkanes on the mitochondrial cell membrane depolarization induced by serum deprivation. (Arbitrary units). Data represent the mean \pm SD of a quadruplicate experiment carried out twice (SD1 and SD2).

Sampling, collection and determination of alkanes (ethane and pentane) and chlorofluoroalkanes (freons)

As the lungs eliminate these compounds, it is advisable, in a first step, to recover the exhaled air without effort, without invasion of the body. An approved machine (CE marking) has been developed for this purpose. It will be enough to breathe, without forcing, in a mouthpiece that the patient simply breathes into. The recovered cartridge will then be analyzed by gas chromatography coupled with mass spectrometry.

Biomarker concentration results reflect the amount of elements you have oxidized/burned and your ability to produce fire extinguishers

The more "ashes" the body produces and uses fire extinguishers, the greater the fire and the greater the damage to the body's cells. The results of alkanes and chlorofluoroalkanes analyses determine what we call biomarkers, those of your oxidative combustion and your fire-fighting capital. It is the globalization of both that is used. The concept of biomarker is not new: glycemia, identified as early as 1848, is a biomarker recognized both to characterize diabetes and to evaluate the efficacy of anti-diabetic molecules.

Biomarkers can be divided into two categories: predictive and prognostic biomarkers.
- A prognostic biomarker can be used to determine the clinical course of a disease, such as the likelihood of survival, recurrence or favourable response to treatment.

- A predictive biomarker is a biomarker that is present in the body before the onset of the disease and that predicts the clinical course of the disease. The predictive value of this biomarker may be positive or negative.

The biomarker that has been analyzed fits into both of these categories. It can be used to predict a pathophysiological disorder and the body's response to it. Measuring this biomarker in a resting situation makes it possible to determine the state of chronic combustion of the organism (which is, for example, different between a group of smokers and a group of non-smokers). Setting up a dynamic test corresponds to igniting a biological fire (not serious for the patient), which completes a possible chronic combustion previously measured and makes it possible to measure the adaptation to an acute combustion situation. By measuring the "basic state" and the "induced state" we can therefore better predict the initial physiopathological situation and apprehend the qualitative and quantitative nature of the organism's ability to "cope".

Peak (SIM, m/z = 101) areas of trichlorotrifluoroethane, tetrafluoroethane, dichlorodifluoromethane before and after mental exercise.

\begin{tabular}{|c|r|r|r|r|r|}
\hline Subjects & $\mathbf{1}$ & $\mathbf{2}$ & $\mathbf{3}$ & $\mathbf{4}$ & $\mathbf{5}$ \\
\hline Before & & & & & \\
Trichlorotrifluoroethane & 296 & 206 & 330 & 60 & 114 \\
Tetrafluoroethane & 2241 & 609 & 795 & 562 & 173 \\
Dichlorodifluoromethane & 456 & 367 & 144 & 106 & 293 \\
\hline After & & & & & \\
Trichlorotrifluoroethane & 8346 & 217 & 1553 & 336 & 316 \\
Tetrafluoroethane & 20201 & 1146 & 18769 & 653 & 377 \\
Dichlorodifluoromethane & 269 & 432 & 764 & 208 & 260 \\
\hline
\end{tabular}

\section{References}

1. Sarbach $C$, Stevens $P$, Whiting J, Puget $P$, Humbert $M$, et al. Evidence of endogenous volatile organic compounds as biomarkers of diseases in alveolar breath. Ann Pharm Fr. 2013; 71: 203-215.

PubMed: https://www.ncbi.nlm.nih.gov/pubmed/23835018

2. Sarbach C, Dugas B, Postaire E. Evidence of variations of endogenous halogenated volatile organic compounds in alveolar breath after mental exercise-induced oxidative stress. Ann Pharm Fr. 2020; 78: 34-41. PubMed: https://www.ncbi.nlm.nih.gov/pubmed/31796267 